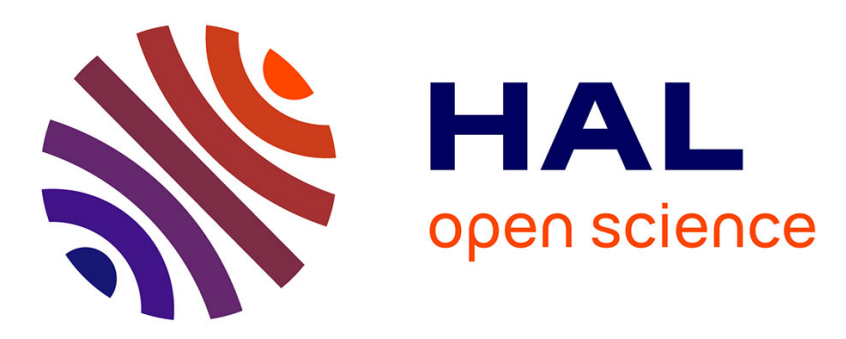

\title{
Resonance assignment of the outer membrane protein AlkL in lipid bilayers by proton-detected solid-state NMR
}

Tobias Schubeis, Tom S Schwarzer, Tanguy Le Marchand, Jan Stanek, Kumar Tekwani Movellan, Kathrin Castiglione, Guido Pintacuda, Loren B Andreas

\section{To cite this version:}

Tobias Schubeis, Tom S Schwarzer, Tanguy Le Marchand, Jan Stanek, Kumar Tekwani Movellan, et al.. Resonance assignment of the outer membrane protein AlkL in lipid bilayers by protondetected solid-state NMR. Biomolecular NMR Assignments, 2020, 10.1007/s12104-020-09964-5 . hal02894006

\section{HAL Id: hal-02894006 https://hal.science/hal-02894006}

Submitted on 8 Jul 2020

HAL is a multi-disciplinary open access archive for the deposit and dissemination of scientific research documents, whether they are published or not. The documents may come from teaching and research institutions in France or abroad, or from public or private research centers.
L'archive ouverte pluridisciplinaire HAL, est destinée au dépôt et à la diffusion de documents scientifiques de niveau recherche, publiés ou non, émanant des établissements d'enseignement et de recherche français ou étrangers, des laboratoires publics ou privés. 


\section{Resonance assignment of the outer membrane protein AlkL in lipid bilayers by proton-detected solid-state NMR}

Tobias Schubeis ${ }^{1}$, Tom S. Schwarzer ${ }^{2}$, Tanguy Le Marchand ${ }^{1}$, Jan Stanek ${ }^{1}$, Kumar Tekwani Movellan $^{3}$, Kathrin Castiglione ${ }^{2} \ddagger$, Guido Pintacuda ${ }^{1 *}$ \& Loren B. Andreas ${ }^{1,3 *}$

${ }^{1}$ Centre de RMN à Très Hauts Champs de Lyon (FRE 2034 - CNRS, UCB Lyon 1, ENS Lyon), Université de Lyon, 5 rue de la Doua, 69100 Villeurbanne, France.

${ }^{2}$ Institute of Biochemical Engineering, Technical University of Munich, Boltzmannstraße 15, 85748 Garching, Germany

${ }^{3}$ Department for NMR-based Structural Biology, Max Planck Institute for Biophysical Chemistry, Am Faßberg 11, 37077 Göttingen, Germany. $\$$ Current address: Institute of Bioprocess Engineering, FAU Erlangen-Nürnberg, Paul-Gordan Str. 3, 91052 Erlangen, Germany

* Corresponding authors: Guido Pintacuda and Loren B Andreas

* Email addresses: guido.pintacuda@ens-lyon.fr, land@nmr.mpibpc.mpg.de

\section{Abstract}

Most commonly small outer membrane proteins, possessing between 8 and $12 \beta$-strands, are not involved in transport but fulfill diverse functions such as cell adhesion or binding of ligands. An intriguing exception are the 8-stranded $\beta$-barrel proteins of the OmpW family, which are implicated in the transport of small molecules. A representative example is AlkL from Pseudomonas putida GPoI, which functions as a passive importer of hydrophobic molecules. This role is of high interest with respect to both fundamental biological understanding and industrial applications in biocatalysis, since this protein is frequently utilized in biotransformation of alkanes. While the transport function of AlkL is generally accepted, a controversy in the transport mechanism still exists. In order to address this, we are pursuing a structural study of recombinantly produced AlkL reconstituted in lipid bilayers using solid-state NMR spectroscopy.

In this manuscript we present ${ }^{1} \mathrm{H},{ }^{13} \mathrm{C}$ and ${ }^{15} \mathrm{~N}$ chemical shift assignments obtained via a suite of 3D experiments employing high magnetic fields $(1 \mathrm{GHz}$ and $800 \mathrm{MHz})$ and the latest magic-angle spinning (MAS) approaches at fast $(60-111) \mathrm{kHz}$ rates. We additionally analyze the secondary structure prediction in comparison with those of published structures of homologous proteins. 


\section{Abbreviations}

IMAC - immobilized metal affinity chromatography, EDTA - ethylenediaminetetraacetic acid, LDAO - lauryldimethylamine N-oxide, OG - n-octyl- $\beta$-D-glucopyranoside, DMPC - 1,2dimyristoyl-sn-glycero-3-phosphocholine, CP - cross polarization, INEPT - insensitive nuclei enhanced by polarization transfer, BASS-SD - band-selective spectral spin diffusion, TOCSY total correlation spectroscopy, MAS - magic-angle spinning

\section{Keywords}

${ }^{1}$ H-detected solid-state NMR, membrane proteins, lipid bilayers, alkane transport, beta-barrel

\section{Biological Context}

Due to the ability to specifically degrade alkanes, the hydroxylase (Alk) system of bacteria such as Pseudomonas putida GPol is of potential interest for the chemical industry in terms of biocatalysis and may even find applications in bioremediation of crude oil pollutions [1]. The catalytic complex is located at the cytoplasmic membrane consisting of AlkB, an integralmembrane non-heme diiron monooxygenase, the rubredoxin $\mathrm{AlkG}$ and the rubredoxin reductase AlkT [2], [3]. These proteins efficiently convert linear alkanes to primary alcohols when in isolation but showed only very limited turnover when engineered into Escherichia coli [4]. This suggests the crucial role of the outer membrane protein AlkL for uptake of medium to long chain alkanes, which are not capable to diffuse through the highly hydrophilic lipopolysaccharide layer at the outer membrane. Indeed, coexpression of AlkL significantly improves whole-cell based hydroxylation of various hydrophobic molecules [5]-[7].

AlkL is counted into the family of OmpW proteins and structures of homologs such as E. coli OmpW (sequence identity 24\%) and Pseudomonas aeruginosa OprG (sequence identity 22\%) have already been solved by X-ray crystallography and solution NMR spectroscopy [8]-[11]. Interestingly, the crystal and NMR structures show a consistent 8 -stranded elliptical $\beta$-barrel but significant differences in the extracellular loops, namely $\beta$-sheets that extend beyond the hydrophobic membrane interior in crystals and long flexible loops in solution. Diffusion of small hydrophobic molecules through a lateral opening into the membrane was suggested as a transport mechanism of OmpW [8]. Due to the increased flexibility in solution, the previous NMR studies were not entirely supportive to this model. One might argue that loops are stabilized by crystal packing or that detergents destabilize the loop structure in solution, what remains evident is the importance of dynamics of the extracellular regions in OmpW proteins.

Here we report the chemical shift assignments of AlkL in DMPC lipid bilayers obtained by ${ }^{1} \mathrm{H}-$ detected solid-state NMR. The use of a fully protonated sample and magic-angle spinning above $100 \mathrm{kHz}$ allowed the combined use of amide-proton and alpha-proton detected spectra for backbone assignment as well as extensive assignment of side-chain ${ }^{13} \mathrm{C}$ and ${ }^{1} \mathrm{H}$ resonances. The lipid environment closely resembles the native membrane and with this sample formulation we anticipate reliable insights into structure and function of AlkL. 


\section{Materials and Methods}

Protein expression and purification; sample preparation

AlkL (28-230) from P. putida GPo1 (Uniprot Q00595) was expressed with a short C-terminal linker and a His-8 tag (in total 219 residues) and purified essentially as described previously [12]. Uniform ${ }^{13} \mathrm{C}$ and ${ }^{15} \mathrm{~N}$ isotope labeling was achieved by the use of M9 minimal media containing 3 $\mathrm{g} / \mathrm{L}{ }^{13} \mathrm{C}$-glucose and $1 \mathrm{~g} / \mathrm{L}{ }^{15} \mathrm{NH}_{4} \mathrm{Cl}$. Deuterated glucose and $\mathrm{D}_{2} \mathrm{O}$ based media were used for ${ }^{2} \mathrm{H}$,

${ }^{13} \mathrm{C},{ }^{15} \mathrm{~N}$-labelled samples. AlkL was extracted from inclusion bodies and purified by IMAC in 50 $\mathrm{mM}$ Tris/ $\mathrm{HCl} \mathrm{pH} \mathrm{8,} 500 \mathrm{mM} \mathrm{NaCl}, 20-500 \mathrm{mM}$ imidazole, $10 \%$ glycerol, $6 \mathrm{M}$ guanidine $\mathrm{HCl}$ and refolded by drop-wise rapid dilution into $20 \mathrm{mM}$ Tris/HCl pH 8, $1 \mathrm{mM}$ EDTA, $1 \mathrm{M}$ Urea, 2\% LDAO. The refolded protein was further purified by anion exchange chromatography in $10 \mathrm{mM}$ TRIS/HCl pH 8, 20-300 mM NaCl, $0.05 \%$ LDAO. The buffer was then exchanged to $20 \mathrm{mM}$ phosphate $\mathrm{pH} 7,2 \% \mathrm{OG}$ using a desalting column. Protein concentrations were estimated based upon the absorption at $280 \mathrm{~nm}$ using a molar extinction coefficient of $34380 \mathrm{M}^{-1} \mathrm{~cm}^{-1}$. DMPC in $1 \%$ OG was added to achieve a protein to lipid ratio of $2: 1$, and the detergent was removed by dialysis against $20 \mathrm{mM}$ phosphate buffer $\mathrm{pH} 7$ using a $20 \mathrm{kDa}$ cutoff membrane. After 2 days the white precipitate was collected by centrifugation, washed with buffer and packed into either 1.3 $\mathrm{mm}$ (deuterated sample) or $0.7 \mathrm{~mm}$ (protonated sample) MAS rotors using an ultracentrifuge packing device (Giotto Biotech).

Solid-state NMR spectroscopy

NMR spectra were recorded using a $0.7 \mathrm{~mm}$ triple-resonance $\left({ }^{1} \mathrm{H},{ }^{13} \mathrm{C},{ }^{15} \mathrm{~N}\right)$ probe on a $1000 \mathrm{MHz}$ Bruker Avance III spectrometer or using a $1.3 \mathrm{~mm}$ triple-resonance $\left({ }^{1} \mathrm{H},{ }^{13} \mathrm{C},{ }^{15} \mathrm{~N}\right)$ probe on a 800 $\mathrm{MHz}$ spectrometer. All data were recorded at the MAS frequency of $111 \mathrm{kHz}(0.7 \mathrm{~mm}$ probe) or 55 to $60 \mathrm{kHz}$ (1.3 mm probe). The temperature of VT nitrogen gas was regulated to maintain a sample temperature of about $310 \mathrm{~K}$. Backbone and sidechain resonance assignments were obtained from a set of three dimensional NMR spectra [13], [14]. Experimental details are given in table S1 and S2. Adamantane was used as the external reference. Spectra were processed using TopSpin 3.5 (Bruker Biospin) or NMRpipe [15] by zero filling to double the number of time increments, and apodization with a squared shifted cosine function (SSB 2 to 3). The direct dimension $\left({ }^{1} \mathrm{H}\right)$ acquisition time was truncated to $8 \mathrm{~ms}$. Spectral analysis and assignment was accomplished with CcpNmr Analysis [16] and Sparky [17]. The signal to noise ratio was estimated from a 1D hNH spectrum with $20 \mathrm{~ms}$ acquisition time, processed with $20 \mathrm{~Hz}$ exponential line broadening.

Sequence alignment and secondary structure analysis

Sequence alignment was performed with the Clustal Omega [18] implementation on the Uniprot server using entries Q00595 (AlkL), P0A915 (OmpW) and Q9HWW1 (OprG). Secondary structure elements of AlkL were predicted from the assigned chemical shifts using TALOS-N [19]. Deposited chemical shifts of OmpW (BMRB Entry 19637) and OprG (BMRB Entry 25768) were reanalyzed using TALOS-N as well. Secondary structure elements of X-ray structures were directly transferred from the respective PDB entries (2F1T and 2X27) 
Results

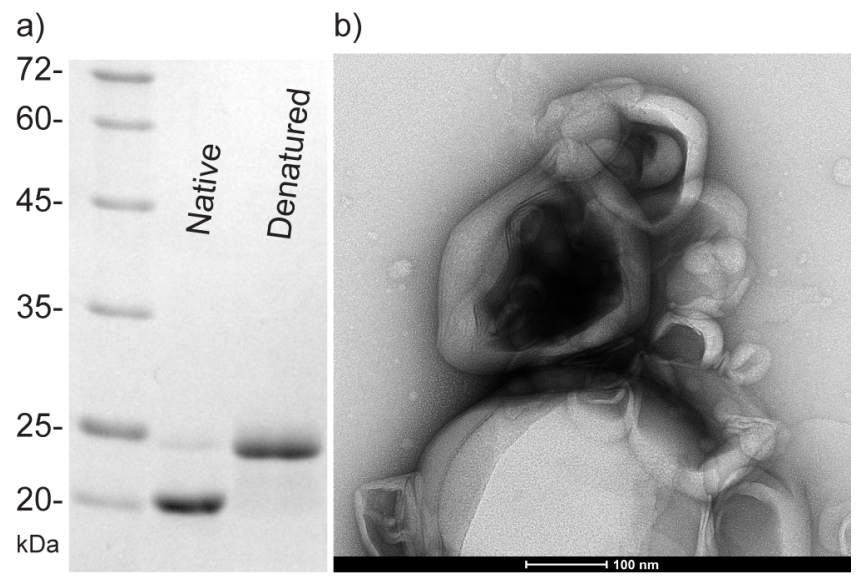

Figure 1 a) SDS-PAGE analysis of purity and folding of AlkL. Folded (Native) sample was incubated with SDSsample buffer at room temperature; the denatured sample was heated to $95 \mathrm{deg}$. C. b) Transmission electron micrographs of multilamellar vesicle preparations containing AlkL

AlkL was expressed by E. coli into inclusion bodies and purified under denaturing conditions followed by refolding into detergent micelles. Denaturation ensured the efficient back exchange of amide protons for the deuterated samples. The refolding efficiency was evaluated from the heatmodifiability of AlkL in SDS-PAGE (Figure 1a). Folded AlkL is denatured inefficiently by SDS at room temperature and migrates differently than the unfolded protein. We estimated the refolding efficiency to $>90 \%$. The yield of ${ }^{13} \mathrm{C},{ }^{15} \mathrm{~N}$ and ${ }^{2} \mathrm{H},{ }^{13} \mathrm{C},{ }^{15} \mathrm{~N}$-labeled protein after purification and refolding was about 20 and $10 \mathrm{mg}$ per liter of culture, respectively. Several types of lipids and different lipid to protein ratios were tested initially with ${ }^{15} \mathrm{~N}$-labeled AlkL as described in [20]. Lipids were saturated with OG detergent, initially forming mixed micelles. Removal of OG by dialysis resulted in the formation of multilamellar vesicles, which appear as a white precipitate. A transmission electron micrograph of the final NMR sample is shown in Figure 1b. The precipitated vesicles were ultracentrifuged into MAS NMR rotors.

The $2 \mathrm{D}{ }^{1} \mathrm{H}-{ }^{15} \mathrm{~N}$ spectrum of deuterated and protonated AlkL are shown in Figure 2a,b. The protonated sample showed an average ${ }^{1} \mathrm{H}$ linewidth of $150 \mathrm{~Hz}$ at $111 \mathrm{kHz}$ MAS, the deuterated sample $90 \mathrm{~Hz}$ at $111 \mathrm{kHz}$ MAS and $120 \mathrm{~Hz}$ at $60 \mathrm{kHz}$ MAS. As concluded elsewhere before, deuteration is still beneficial for ${ }^{1} \mathrm{H}$ linewidth and coherence lifetimes, even at $>100 \mathrm{kHz}$ MAS [21], [22]. Even though the fully protonated sample showed a lower resolution most assignments were made on this sample. While a deuterated samples only permits the classic set of ${ }^{1} \mathrm{H}^{\mathrm{N}}$-detected triple-correlation spectra for backbone sequential assignment, it was useful in assigning loop residues for which peak intensities were lower. Fully protonated samples allow recording of an additional set of ${ }^{1} \mathrm{H} \alpha$-detected spectra, which exploit the favorable resolution of the $2 \mathrm{D} \mathrm{C} \alpha-\mathrm{H} \alpha$ fingerprint. The ${ }^{13} \mathrm{C} \alpha$ region of $2 \mathrm{D}{ }^{1} \mathrm{H}^{-13} \mathrm{C}$ correlation spectra of AlkL, reconstituted in DMPC, is shown in Figure 2c. $\alpha$-protons also display ${ }^{1} \mathrm{H}$ linewidth of approximately $150 \mathrm{~Hz}$, which is in line with non-crystalline membrane protein samples studied previously and indicative for high sample homogeneity [23], [24]. The decent signal to noise ratio $\left(\mathrm{S} / \mathrm{N} / \sqrt{t}_{\mathrm{t}}=24.7\right)$ and long refocused 
a)

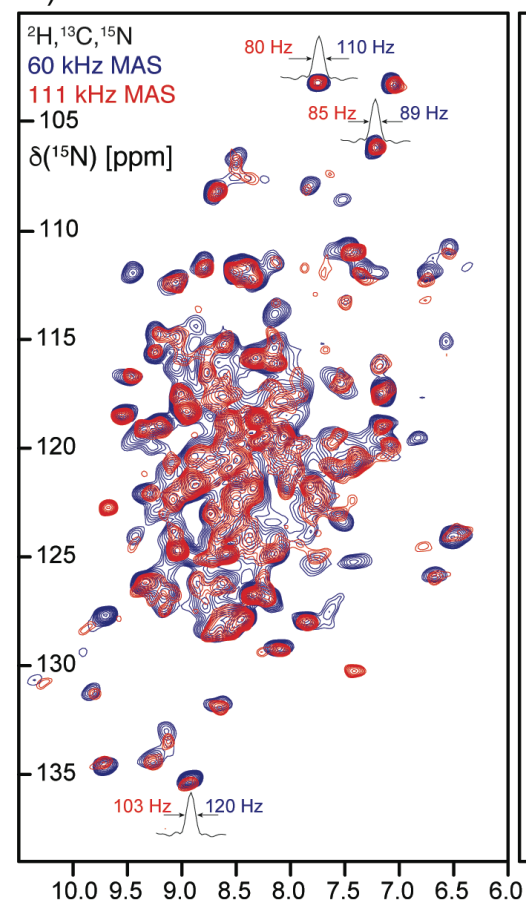

b)

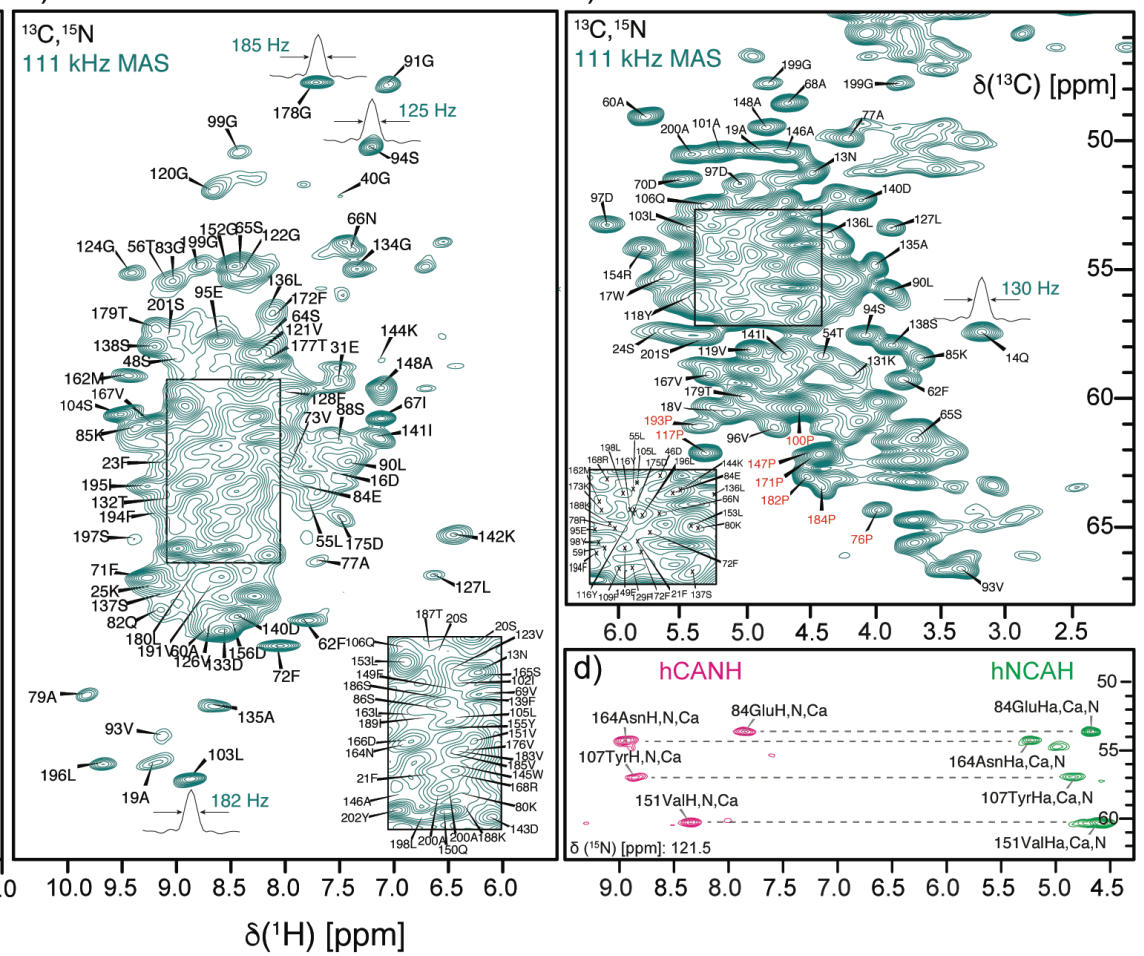

Figure 2 a) $2 \mathrm{D}^{1} \mathrm{H}_{-}{ }^{15} \mathrm{~N}$ correlation spectra $(\mathrm{hNH})$ of ${ }^{2} \mathrm{H}\left(100 \%{ }^{1} \mathrm{H}^{\mathrm{N}}\right),{ }^{13} \mathrm{C},{ }^{15} \mathrm{~N}$-labeled AlkL in DMPC vesicles recorded on a sample packed in a $1.3 \mathrm{~mm}$ rotor with $60 \mathrm{kHz}$ MAS (blue) or in a $0.7 \mathrm{~mm}$ rotor with $111 \mathrm{kHz}$ MAS on a $1 \mathrm{GHz}$ spectrometer. b) hNH spectrum of fully protonated ${ }^{13} \mathrm{C},{ }^{15} \mathrm{~N}$-labeled AlkL recorded with $111 \mathrm{kHz}$ MAS. c) ${ }^{13} \mathrm{C} \alpha-{ }^{1} \mathrm{H} \alpha$ region of $2 \mathrm{D}{ }^{1} \mathrm{H}-{ }^{13} \mathrm{C}$ correlation spectrum $(\mathrm{hCH})$ of fully protonated ${ }^{13} \mathrm{C},{ }^{15} \mathrm{~N}$ labeled AlkL recorded with $111 \mathrm{kHz}$ MAS. d) Slice of two $3 \mathrm{D}^{1} \mathrm{H}_{-}{ }^{13} \mathrm{C}-{ }^{15} \mathrm{~N}$ correlation spectra (hCANH and hNCAH) at the ${ }^{15} \mathrm{~N}$ frequency of $121.5 \mathrm{ppm}$. The spectra were recorded simultaneously on fully protonated AlkL. Sequence specific resonance assignments are annotated on peaks in panel $\mathrm{b}, \mathrm{c}$ and $\mathrm{d}$.

transverse coherence lifetimes $\left(\mathrm{T}_{2}{ }^{*}\right)$ of $3.6 \mathrm{~ms}\left({ }^{1} \mathrm{H}^{\mathrm{N}}\right), 18 \mathrm{~ms}\left({ }^{15} \mathrm{~N}\right), 12.2 \mathrm{~ms}\left({ }^{13} \mathrm{C} \alpha\right)$ and $17 \mathrm{~ms}\left({ }^{13} \mathrm{C}^{\prime}\right)$ obtained for the sample at $110 \mathrm{kHz}$ allowed the acquisition of an extensive set of three dimensional spectra. The combination of amide and $\alpha$-proton detected spectra proved to be very powerful for sequence specific resonance assignment. While in the classic amide-based backbone walk both the ${ }^{1} \mathrm{H}^{\mathrm{N}}$ and ${ }^{15} \mathrm{~N}$ chemical shift of a pre/succeeding residue needs to be identified, the ${ }^{1} \mathrm{H \alpha}$ detected spectra add the sequential ${ }^{15} \mathrm{~N}$ chemical shift, facilitating the linkage dramatically. The strategy relies on the identification of ${ }^{1} \mathrm{H}^{\mathrm{N}},{ }^{1} \mathrm{H \alpha},{ }^{13} \mathrm{C} \alpha$ and ${ }^{15} \mathrm{~N}$ resonances of individual spin-systems (i.e. intraresidue correlations) which is, fortunately, often straightforward, using the hCANH and hNCAH spectra as demonstrated in Figure 2d. The spectra in Figure 2d were acquired simultaneously to improve sensitivity and maximize consistency of chemical shifts [25], [26]. The succeeding ${ }^{15} \mathrm{~N}(\mathrm{i}+1)$ chemical shift can then be found in the $\mathrm{hNcoCAH}$ spectrum and adjacent residues are simply linked over the ${ }^{13} \mathrm{C} \alpha$ resonance. Additional ${ }^{13} \mathrm{C}^{\prime}$ and ${ }^{13} \mathrm{C} \beta$ correlations resolved most of remaining ambiguities, finally resulting in backbone assignments of 172 (out of 219) residues, corresponding to $79 \%$ total and more than $90 \%$ of the detectable residues. An overview of assigned heteronuclei is provided in figure S2. Most unassigned residues are located at the Nand C-termini and in the region between residues 33 and 53. These fragments likely show increased 
dynamics and are therefore undetectable in the CP-based MAS spectra. In general, the highest peak intensity was observed in the transmembrane $\beta$-strands, while the loop regions were more challenging to assign due to lower signal intensity. The automated assignment algorithm FLYA was employed to jointly analyze the large set of correlation spectra and already identified the transmembrane $\beta$-strands. Manual analysis was necessary to extend these assignments into loop residues. High sensitivity data, recorded on a deuterated sample in a larger $1.3 \mathrm{~mm}$ rotor, was particularly useful to add assignments to loop 1 (residues 22-47), a region of general low peak intensity, and to define the $\beta$-strand edges. All obtained resonance assignments are annotated in Figure $2 \mathrm{~b}$ and $\mathrm{c}$. Note the assigned proline residues, marked in red in Figure $2 \mathrm{c}$, that are unavailable from amide proton based assignment spectra. A representative strip plot for the assignments of residues 83 to 87 is shown in Figure $\mathrm{S} 1$. The amide ${ }^{1} \mathrm{H}^{\mathrm{N}}$ and ${ }^{15} \mathrm{~N}$ assignments were further crosschecked using a 3D NNH spectrum based on proton-proton BASS-SD mixing [27]. We found that for $\beta$-strands, the transfer to neighboring amide protons was particularly efficient using this technique. The assigned ${ }^{13} \mathrm{C} \alpha-{ }^{1} \mathrm{H} \alpha$ pairs additionally provided a starting point to the analysis of a 3D CCH-TOCSY and a 4D HCCH-TOCSY spectra, which allowed the assignment of the majority of the sidechain aliphatic ${ }^{13} \mathrm{C}$ and ${ }^{1} \mathrm{H}$ resonances [14]. We did not record additional spectra to assign the aromatic ring resonances.

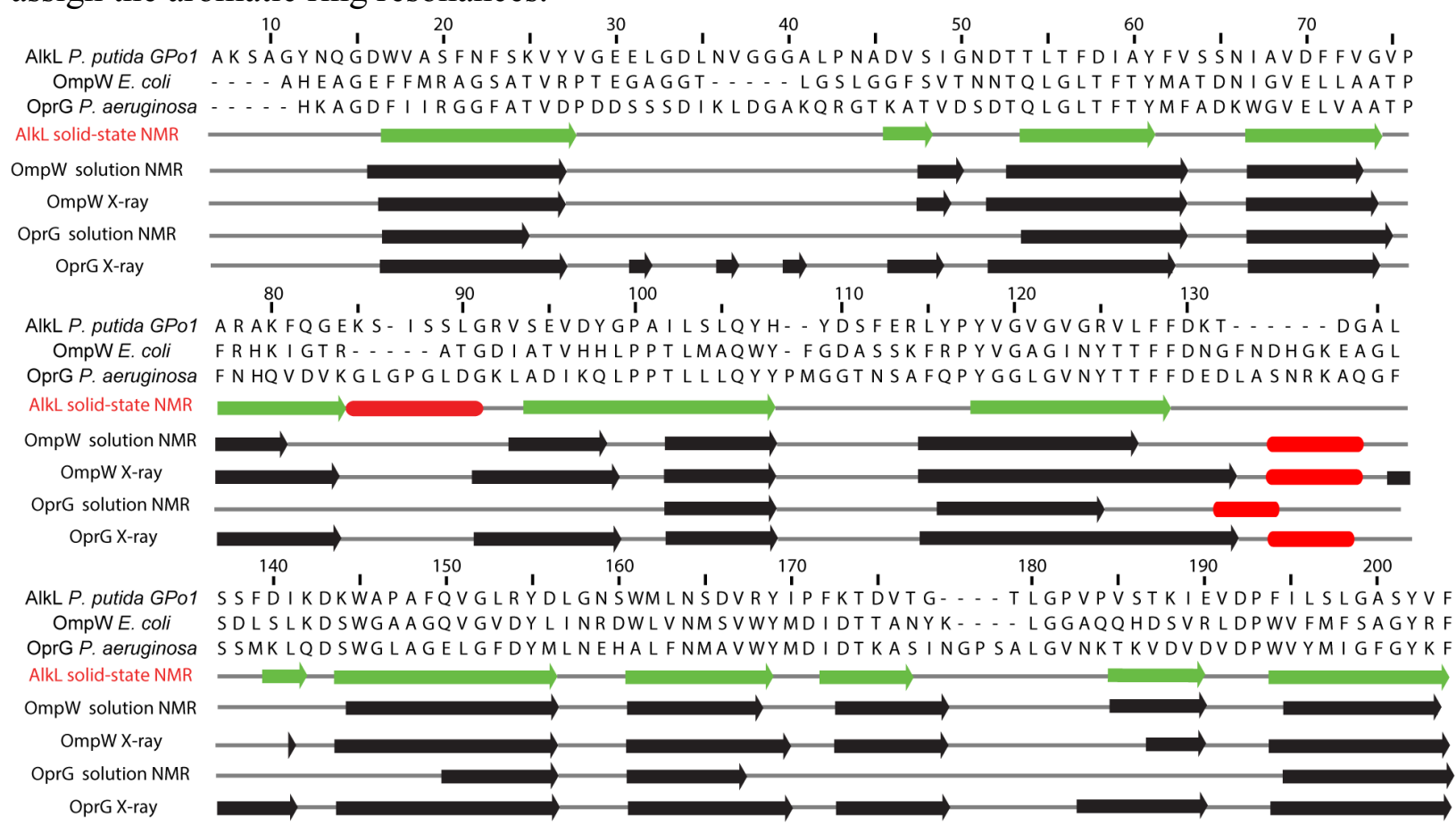

Figure 3: Sequence alignment and secondary structure analysis of the proteins AlkL, OmpW and OprG. Backbone torsion angles were calculated from NMR chemical shifts using TALOS-N or directly extracted from PDB files for $\mathrm{X}$-ray crystal structures. $\beta$-strands are plotted as green or black arrows, and $\alpha$-helices as red rounded rectangles.

The degree of protein folding in the extracellular domain of OmpW proteins is highly dependent on the experimental conditions and showed discrepancies between previously published X-ray and solution NMR studies of OmpW and OprG. Analysis of the chemical shifts towards the secondary structure of AlkL revealed $13 \beta$-strands and one short $\alpha$-helix (Figure 3 ). The positions of the $\beta$ - 
strands are in good agreement with the X-ray structures of OmpW and OprG, proving that extensive folding of the extracellular domain is present in our DMPC preparation. The helix in AlkL is located in a different region compared to the other two proteins.

In conclusion, we have found experimental conditions that are close to the native environment of this outer membrane protein, and importantly also favor to a protein fold close the one previously observed via X-ray crystallography. We anticipate to gain new insight into the transport mechanism of the protein by applying further NMR measurements sensitive to dynamics and interactions with small molecules.

\section{Accession Number}

${ }^{1} \mathrm{H},{ }^{13} \mathrm{C}$ and ${ }^{15} \mathrm{~N}$ backbone and side-chain chemical shifts of the outer membrane protein AlkL have been deposited in the BioMagResBank (http://www.bmrb.wisc.edu) under the accession number 34365 .

\section{Acknowledgments}

We thank the cryoEM facility of the MPI-BPC for recording the negative stain images. The work was funded by the European Research Council (ERC-2015-CoG GA 648974 to GP), by the CNRS (IR-RMN FR3050), by the EC (project iNext GA 653706), by the German Research Foundation (Emmy Noether program grant AN1316/1-1 and SFB803 grant INST 186/794-3 to LBA) and by the German Federal Ministry of Education and Research (BMBF GA 031A178 to KC).

\section{References}

[1] L. Meng, W. Li, M. Bao, and P. Sun, "Promoting the treatment of crude oil alkane pollution through the study of enzyme activity," Int. J. Biol. Macromol., vol. 119, pp. 708-716, Nov. 2018.

[2] J. B. van Beilen, M. Neuenschwander, T. H. M. Smits, C. Roth, S. B. Balada, and B. Witholt, "Rubredoxins involved in alkane oxidation.," J. Bacteriol., vol. 184, no. 6, pp. 1722-32, Mar. 2002.

[3] J. B. van Beilen and E. G. Funhoff, "Alkane hydroxylases involved in microbial alkane degradation," Appl. Microbiol. Biotechnol., vol. 74, no. 1, pp. 13-21, Feb. 2007.

[4] R. R. Chen, "Permeability issues in whole-cell bioprocesses and cellular membrane engineering," Appl. Microbiol. Biotechnol., vol. 74, no. 4, pp. 730-738, Feb. 2007.

[5] M. K. Julsing, M. Schrewe, S. Cornelissen, I. Hermann, A. Schmid, and B. Bühler, "Outer Membrane Protein AlkL Boosts Biocatalytic Oxyfunctionalization of Hydrophobic Substrates in Escherichia coli," Appl. Environ. Microbiol., vol. 78, no. 16, pp. 5724-5733, Aug. 2012.

[6] S.-C. Hsieh, J.-H. Wang, Y.-C. Lai, C.-Y. Su, and K.-T. Lee, "Production of 1-Dodecanol, 1-Tetradecanol, and 1,12-Dodecanediol through Whole-Cell Biotransformation in Escherichia coli.," Appl. Environ. Microbiol., vol. 84, no. 4, pp. e01806-17, Feb. 2018.

[7] Y. M. van Nuland, G. Eggink, and R. A. Weusthuis, "Application of AlkBGT and AlkL from Pseudomonas putida GPo1 for Selective Alkyl Ester $\omega$-Oxyfunctionalization in Escherichia coli," Appl. Environ. Microbiol., vol. 82, no. 13, pp. 3801-3807, Jul. 2016.

[8] H. Hong, D. R. Patel, L. K. Tamm, and B. van den Berg, "The Outer Membrane Protein OmpW Forms an Eight-stranded $\beta$-Barrel with a Hydrophobic Channel," J. Biol. Chem., vol. 281, no. 11, pp. 7568-7577, Mar. 2006.

[9] D. S. Touw, D. R. Patel, and B. van den Berg, "The Crystal Structure of OprG from Pseudomonas aeruginosa, a Potential Channel for Transport of Hydrophobic Molecules across the Outer Membrane," PLoS One, vol. 5, no. 11, p. e15016, Nov. 2010.

[10] R. Horst, P. Stanczak, and K. Wüthrich, "NMR Polypeptide Backbone Conformation of the E. coli Outer Membrane Protein W," Structure, vol. 22, no. 8, pp. 1204-1209, Aug. 2014. 
[11] I. Kucharska, P. Seelheim, T. Edrington, B. Liang, and L. K. Tamm, "OprG Harnesses the Dynamics of its Extracellular Loops to Transport Small Amino Acids across the Outer Membrane of Pseudomonas aeruginosa," Structure, vol. 23, no. 12, pp. 2234-2245, Dec. 2015.

[12] T. S. Schwarzer, M. Hermann, S. Krishnan, F. C. Simmel, and K. Castiglione, "Preparative refolding of small monomeric outer membrane proteins," Protein Expr. Purif., vol. 132, pp. 171-181, Apr. 2017.

[13] E. Barbet-Massin et al., "Rapid Proton-Detected NMR Assignment for Proteins with Fast Magic Angle Spinning," J. Am. Chem. Soc., vol. 136, no. 35, pp. 12489-12497, Sep. 2014.

[14] J. Stanek et al., "NMR Spectroscopic Assignment of Backbone and Side-Chain Protons in Fully Protonated Proteins: Microcrystals, Sedimented Assemblies, and Amyloid Fibrils," Angew. Chemie Int. Ed., vol. 55, no. 50, pp. 15504-15509, Dec. 2016.

[15] F. Delaglio, S. Grzesiek, G. Vuister, G. Zhu, J. Pfeifer, and A. Bax, "NMRPipe: A multidimensional spectral processing system based on UNIX pipes," J. Biomol. NMR, vol. 6, no. 3, pp. 277-293, Nov. 1995.

[16] W. F. Vranken et al., "The CCPN data model for NMR spectroscopy: Development of a software pipeline," Proteins Struct. Funct. Genet., vol. 59, no. 4, pp. 687-696, 2005.

[17] W. Lee, M. Tonelli, and J. L. Markley, "NMRFAM-SPARKY: enhanced software for biomolecular NMR spectroscopy," Bioinformatics, vol. 31, no. 8, pp. 1325-1327, Apr. 2015.

[18] F. Sievers et al., "Fast, scalable generation of high-quality protein multiple sequence alignments using Clustal Omega," Mol. Syst. Biol., vol. 7, no. 1, 2011.

[19] Y. Shen and A. Bax, "Protein backbone and sidechain torsion angles predicted from NMR chemical shifts using artificial neural networks," J. Biomol. NMR, vol. 56, no. 3, pp. 227-241, 2013.

[20] T. Schubeis, T. Le Marchand, L. B. Andreas, and G. Pintacuda, "1H magic-angle spinning NMR evolves as a powerful new tool for membrane proteins," J. Magn. Reson., vol. 287, pp. 140-152, Feb. 2018.

[21] K. Xue et al., "Limits of Resolution and Sensitivity of Proton Detected MAS Solid-State NMR Experiments at $111 \mathrm{kHz}$ in Deuterated and Protonated Proteins," Sci. Rep., vol. 7, no. 1, 2017.

[22] D. Cala-De Paepe, J. Stanek, K. Jaudzems, K. Tars, L. B. Andreas, and G. Pintacuda, "Is protein deuteration beneficial for proton detected solid-state NMR at and above $100 \mathrm{kHz}$ magic-angle spinning?," Solid State Nucl. Magn. Reson., vol. 87, pp. 126-136, 2017.

[23] D. Lalli et al., "Proton-Based Structural Analysis of a Heptahelical Transmembrane Protein in Lipid Bilayers," J. Am. Chem. Soc., vol. 139, no. 37, pp. 13006-13012, Sep. 2017.

[24] N.-A. Lakomek, L. Frey, S. Bibow, A. Böckmann, R. Riek, and B. H. Meier, "Proton-Detected NMR Spectroscopy of Nanodisc-Embedded Membrane Proteins: MAS Solid-State vs Solution-State Methods," J. Phys. Chem. B, vol. 121, no. 32, pp. 7671-7680, Aug. 2017.

[25] J. Stanek, T. Schubeis, P. Paluch, P. Güntert, L. B. Andreas, and G. Pintacuda, "Automated backbone NMR resonance assignment of large proteins using redundant linking from a single simultaneous acquisition," $J$. Am. Chem. Soc., p. jacs.0c00251, 2020.

[26] K. Sharma, P. K. Madhu, V. Agarwal, and K. R. Mote, "Simultaneous recording of intra- and inter-residue linking experiments for backbone assignments in proteins at MAS frequencies higher than $60 \mathrm{kHz}, " J$. Biomol. NMR, 2020.

[27] M. G. Jain et al., "Selective ${ }^{1} \mathrm{H}-{ }^{1} \mathrm{H}$ Distance Restraints in Fully Protonated Proteins by Very Fast MagicAngle Spinning Solid-State NMR," J. Phys. Chem. Lett., vol. 8, no. 11, pp. 2399-2405, Jun. 2017. 